\title{
Redox signaling in pathophysiology of hypertension
}

\author{
Miroslava Majzunova', Ima Dovinova ${ }^{1 *}$, Miroslav Barancik ${ }^{2}$ and Julie YH Chan ${ }^{3 *}$
}

\begin{abstract}
Reactive oxygen species (ROS) are products of normal cellular metabolism and derive from various sources in different cellular compartments. Oxidative stress resultant from imbalance between ROS generation and antioxidant defense mechanisms is important in pathogenesis of cardiovascular diseases, such as hypertension, heart failure, atherosclerosis, diabetes, and cardiac hypertrophy. In this review we focus on hypertension and address sources of cellular ROS generation, mechanisms involved in regulation of radical homeostasis, superoxide dismutase isoforms in pathophysiology of hypertension; as well as radical intracellular signaling and phosphorylation processes in proteins of the affected cardiovascular tissues. Finally, we discuss the transcriptional factors involved in redox-sensitive gene transcription and antioxidant response, as well as their roles in hypertension.
\end{abstract}

Keywords: Radical signaling, Antioxidant response, Kinase pathway, Transcriptional factor, Reactive oxygen species, Hypertension, Redox-sensitive signaling

\section{Review}

\section{Introduction}

Living organisms can reduce oxygen to water via aerobic oxidative phosphorylation. This significantly shapes cellular metabolism and energy production. The associated oxygen intake results in the formation of toxic reactive oxygen species (ROS) in the mitochondrial respiratory chain. These radicals are electron donors and can damage DNA, RNA, proteins, and lipids. They can also propagate deleterious reactions throughout cells and tissues resulting in cell death and apoptosis [1]. In addition, ROS can alter gene expression by modulating the activation of transcription factors, with subsequent influence on downstream target proteins that regulate cellular functions such as cell growth and differentiation, modulate production and degradation of extracellular matrix, inactivate nitric oxide $(\mathrm{NO})$ functions, and stimulate multiple kinases and proinflammatory gene expressions. The ROS play an important role in the development of cardiovascular diseases such as hypertension, heart

\footnotetext{
* Correspondence: Ima.Dovinova@savba.sk; jchan@cgmh.org.tw ${ }^{1}$ Institute of Normal and Pathological Physiology, Slovak Academy of Sciences, Sienkiewiczova 1, 81371 Bratislava, Slovakia

${ }^{3}$ Center for Translational Research in Biomedical Sciences, Kaohsiung Chang Gang Memorial Hospital, Kaohsiung, Taiwan

Full list of author information is available at the end of the article
}

failure, atherosclerosis, diabetes, and cardiac hypertrophy. Increased production of oxidants, reduced NO bioavailability and reduced capacity of antioxidants in the vascular system and kidneys are involved in these diseases [2].

Studies of the role of ROS and reactive nitrogen species (RNS) in signal transduction have grown in number during the past decade. The main interest in the field is to recognize the specific targets and chemical reactions involved in the signaling pathways triggered by ROS and RNS as second messenger molecules. It was observed that cysteine residues in the thiolate (ionized) form are present in several classes of signaling proteins, and these can be the specific targets for reactions with hydrogen peroxide $\left(\mathrm{H}_{2} \mathrm{O}_{2}\right)$ and $\mathrm{RNS}$. These findings suggest that in many signaling events where ROS and RNS take part, enzymatic catalysis is more likely to be involved than a non-enzymatic reaction [3]. As such, aberrant redoxsensitive signal transduction is involved in pathophysiology of hypertension [4-7]. In this review, it is not our intention to provide a detailed survey on literature of ROS in pathogenesis of hypertension, since many comprehensive reviews in this aspect are available [8-12]. We shall focus on different sources of ROS in the cardiovascular systems and summarize current knowledge on the redox-sensitive signaling in pathophysiology of hypertension. 


\section{ROS generation}

Several mechanisms or pathways are responsible for the production of free radicals in the cell $[13,14]$. A paradigm has arisen over the past several years whereby small amounts of radicals (so called "kindling radicals") can lead to formation of peroxynitrite, which oxidizes tetrahydrobiopterin $\left(\mathrm{BH}_{4}\right)$, leading to uncoupling of the endothelial NO synthase (eNOS) and to formation of large amounts of "bonfire" radicals [15]. As a result, production of one free radical can lead to formation of other radicals through a sequential chain reaction. According to this "kindling-bonfire" theory of vascular oxidative stress, there are primary, secondary and tertiary sources of ROS. In general, nicotinamide adenine dinucleotide phosphate (NADPH) oxidase acts as the primary source of superoxide anions $\left(\mathrm{O}_{2}^{-*}\right)$ and $\mathrm{H}_{2} \mathrm{O}_{2}$ in the vessel wall. NADPH oxidase-derived ROS then act as "kindling" and activate secondary (uncoupled eNOS, xanthine oxidase), and tertiary (mitochondrial) sources of ROS, which contribute to the "bonfire" of radicals and oxidative stress seen at later stages of diseases [16] (Figure 1).

\section{NADPH oxidase-derived ROS and hypertension}

ROS are derived from many sources in different cellular compartments. In the vascular smooth muscle cells and endothelial cells, NADPH oxidase acts as the primary source and is particularly important in pathophysiology of hypertension (Figure 1). In the vascular system, ROS production via the NADPH oxidase is triggered by stimulation of neurohumoral vasoconstrictor agents, such as angiotensin II (Ang II), endothelin-1 (ET-1) and norepinephrine (NE). The action of Ang II through angiotensin type $1\left(\mathrm{AT}_{1}\right)$ receptors plays an important role in vasoconstriction. Activation of AT1 receptors results in induction of a number of ROSproducing events in the cell. Infusion of Ang II to normotensive rats stimulates the production of $\mathrm{O}_{2}^{-*}$ by $\mathrm{NADPH}$ oxidase in vessels and induces pressor responses [17]. NADPH oxidase can also be activated by aldosterone and ET-1 [18]. ET-1, the main endothelin form in the endothelium, is a potent vasoconstrictor produced in various vascular tissues including the endothelium. When delivered in high concentrations, ET-1 acts as a vasoconstrictor and is able to alter arterial pressure. The effects of ET-1 are mediated by two isoforms of receptors, $\mathrm{ET}_{\mathrm{A}}$ and $\mathrm{ET}_{\mathrm{B}}$. Activation of $\mathrm{ET}_{\mathrm{A}}$ receptors causes contraction of blood vessels via activation of the NADPH oxidase and generation of ROS; activation of $\mathrm{ET}_{\mathrm{B}}$ receptors leads to relaxation of vessels [19]. In cardiomyocytes, the production of ROS is stimulated also by NE via $\alpha_{1}$-adrenergic receptors $\left(\alpha_{1}-\mathrm{AR}\right) . \alpha_{1}-\mathrm{AR}, \mathrm{AT}_{1}$, and ET-1 receptors are known to activate NADPH oxidase through the G-protein, resulting in the production of ROS [20]. Significance of

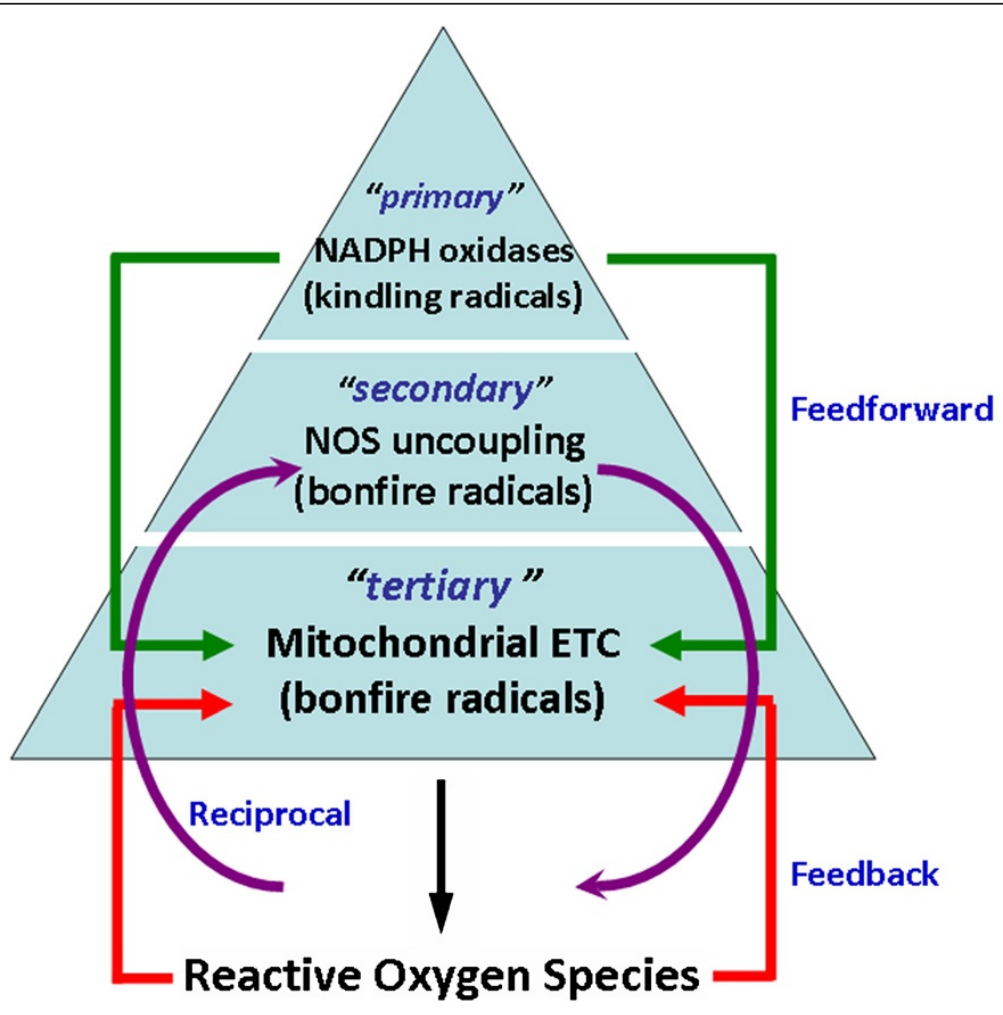

Figure 1 ROS sources and their function according to "kindlig-bonfire" theory. 
the NADPH oxidase-derived ROS in pathogenesis of hypertension was comprehensively discussed in several recent reviews [12,21-23].

\section{NOS uncoupling and hypertension}

Under physiological conditions, NOS, in the presence of substrate L-arginine and co-factor $\mathrm{BH}_{4}$, produces $\mathrm{NO}$. When $\mathrm{BH}_{4}$ levels are reduced, stability of NOS dimer formation is altered such that the oxidase domain yields molecular uncoupling and the catalytic activity becomes functionally 'uncoupled' [12]. Enzymatic reduction of molecular oxygen by eNOS no longer couples to L-arginine, resulting in the generation of deleterious $\mathrm{O}_{2}^{-*}$ rather than protective NO [24]. This eNOS uncoupling (Figure 1) contributes to the increased ROS production and endothelial dysfunction observed in various vascular diseases [25,26], including hypertension [27]. Detailed discussion on significance of eNOS uncoupling in pathogenesis of hypertension is beyond the scope of this review and readers are recommended to read other reviews [26-28] for detailed discussion.

\section{Mitochondrial ROS and hypertension}

Mitochondrial electron transport chain is another important source of ROS generation. Any damage at enzyme complexes of the mitochondrial respiratory chain leads to dysfunction of the mitochondrial respiration with subsequent transfer of electrons to molecular oxygen increasing the mitochondrial $\mathrm{O}_{2}^{-*}$ and $\mathrm{H}_{2} \mathrm{O}_{2}$ formation [29]. In addition, increased mitochondrial peroxynitrite formation leads to nitration and inactivation of mitochondrial antioxidant, manganese superoxide dismutase (MnSOD) [30], which results in the impaired breakdown of mitochondrial $\mathrm{O}_{2}^{-\bullet}$ and further exacerbating in ROS production. Finally, cytosolic ROS, via opening of the redox-dependent mitochondrial ATP-sensitive potassium channels [31] and changes in the mitochondrial membrane potential [32], stimulates the mitochondrial ROS formation (Figure 1). Reduced capacity of the mitochondrial respiratory chain was observed in the brain stem of the spontaneously hypertensive rats (SHR) and in neurogenic hypertension induced by Ang II [33].

Mitochondria are integral component in energy metabolism, ROS generation, and cell signaling, thus play an important role in oxidative stress leading to the development of many cardiovascular conditions, including hypertension. The functional significance of mitochondriaderived ROS, particularly in vascular cells, has recently received a great attention. For example, hyperinsulinemia induces migration and proliferation of vascular smooth muscle cells via the increase in mitochondrial ROS [34]. Interestingly, production of free radicals and impairment of mitochondrial function in young SHR has been affected after long-term treatment with $\mathrm{AT}_{1} \mathrm{R}$ blocker, losartan.
Glutamate-supported respiration, the rate of ATP production, and concentrations of coenzyme Q9 (CoQ9), coenzyme Q10 (CoQ10), and alpha-tocopherol have all been reported to improve mitochondrial dysfunctions and promote antihypertension in SHR after the therapy [35].

During acute hypoxia, $\mathrm{O}_{2}^{-\bullet}$ released from mitochondrial Complex III of smooth muscle cells diffuses into the cytosol and triggers increases in intracellular calcium and causes acute hypoxic pulmonary vasoconstriction [36,37]. Moreover, mitochondrial ROS cross-talk with NADPH oxidase markedly augments redox responses to Ang II in the vascular smooth muscle cells [38]. This cross-talk between mitochondrial ROS and the NADPH oxidase in the rostral ventrolateral medulla (RVLM), key nucleus for the generation of sympathetic outflow from the brain stem, was recently demonstrated to play an active role in manifestation of high arterial pressure in SHR [39].

\section{Redox-sensitive intracellular signaling in hypertension}

The term "redox signaling" describes a process in which physiological levels of ROS induce modifications to proteins that are discrete, site-specific, and reversible [40]. Evidence emerged over the past 2 decades suggests that ROS modulate the activity of a vast array of intracellular proteins and signaling pathways, and this redox signaling is spatially and temporally regulated to generate specific cellular effects under health and disease.

Until recently, ROS were considered only as harmful molecules. However, recent studies suggest that ROS may serve as an important physiological regulator of intracellular phosphorylation signaling pathways. The specific effects of ROS are largely modulated by covalent modification of specific cysteine residues, which were discovered in redoxsensitive proteins. Oxidation of these reactive cysteine residues can lead to reversible modification of enzyme activity. There is evidence that the ROS regulate various physiological parameters in response to stimulation with growth factors to generate inflammatory response. Disruption of normal ROS signaling may lead to several diseases in humans, including hypertension [41]. In hypertension, neurohumoral stimuli such as Ang II, NE, and ET-1 activate receptors located on cell membrane, namely AT1, $\alpha-A R$, and ET receptors. The function of these receptors is coupled to $\mathrm{G}$ proteins, which activate the source of ROS, NADPH oxidase. The activated NADPH oxidase will produce ROS (e.g., $\mathrm{O}_{2}^{-*}$ ), and these, in turn, activate cell phosphorylation pathways: the mitogen-activated protein kinases (MAPKs), tyrosine kinases, and phosphoinositol3-kinase/Akt kinase (PI3K/Akt). The activated phosphorylation pathways activate transcription factors such as activated protein-1 (AP-1), p53, nuclear factor kappa B (NFkB), and nuclear E2-related factor 2 (Nrf2), which stimulate transcription of genes after moving into the nucleus. Proteins encoded by these target genes in turn 
mediate cellular consequences leading to changes in the phenotypes, such as hypertrophy, inflammation, necrosis and apoptosis of cells and, on the other hand, stimulate the production of antioxidants involved in antioxidant defense [17,20,41] (Figure 2).

Despite the fact that cells of different systems involved in the regulation of blood pressure perform different functions, the redox signaling is by and large very similar and unveil no apparent differences among these types of cells. NADPH oxidases are primary resources of ROS in the endothelial cells, vascular smooth muscle cells, cardiomyocytes, cells of kidneys, as well as cardiovascular neurons (regions such as the circumventricular organs, paraventricular nucleus of the hypothalamus, nucleus tractus solitarii and RVLM) in the brain [10,12,21,42-44]. Ang II is important activator of NADPH oxidases and stimulator of ROS production in all types of cells [20,42-46]. Production of ROS is stimulated by shear and mechanical stress in the vascular smooth muscle cells and cardiomyocytes, respectively. In addition, MAPKs are responsible for major effects of ROS such as proliferation, hypertrophy, and apoptosis in these cells [20,42,45-47]. The same signaling is also proposed to mediate the increase in sympathetic nerve activity, vasopressin release and drinking behavior induced by Ang II (Table 1).

\section{Mitogen-activated protein kinases}

The MAPK family includes serine-threonine protein kinases that play an important role in the transmission of extracellular signals from cell membrane to the nucleus. Activation of MAPKs and signal transduction depends on series of phosphorylating events that allow interaction of multiple signaling pathways. MAPK phosphorylation cascades can be negatively regulated by MAP phosphatases that dephosphorylate/deactivate individual MAPKs [49]. The MAPK pathways are involved in the regulation of cell proliferation, differentiation, transformation and death, as well as in vasoconstriction [50]. Three main subgroups of MAPKs were discovered in the vascular system of mammals: (a) extracellular signal-regulated kinases (ERKs); (b) c-Jun N-terminal kinases (JNKs); (c) p38-MAPK. MAPK pathways; all can be activated by many extracellular and intracellular stimuli such as growth factors (Ang II, vascular endothelial growth factor, platelet-derived growth factor) [51], inflammatory cytokines, and cellular stress [52]. Oxidative stress is a particular type of such stress that induces activation of MAPK pathways [53]. Studies have shown that increased production of ROS is responsible for activation of redox-sensitive p38-MAPK, which might be involved in the functional and structural changes associated with hypertension [54]. In SHR, p38-MAPK is essential for collagen synthesis and mediates the growth of vascular smooth muscle cells [51]. The major source of ROS involved in kinase activation is NADPH oxidase. Although the precise mechanisms of redox-sensitive MAPK activation are not fully understood, the likely mechanisms include: (a) oxidation of cysteine residues of receptors for growth factors and cytokines; (b) oxidative modification of intracellular kinases involved in the MAPK signaling cascade; (c) deactivation and degradation of MAPK phosphatases that maintain the MAPK pathway in the inactive state [52].

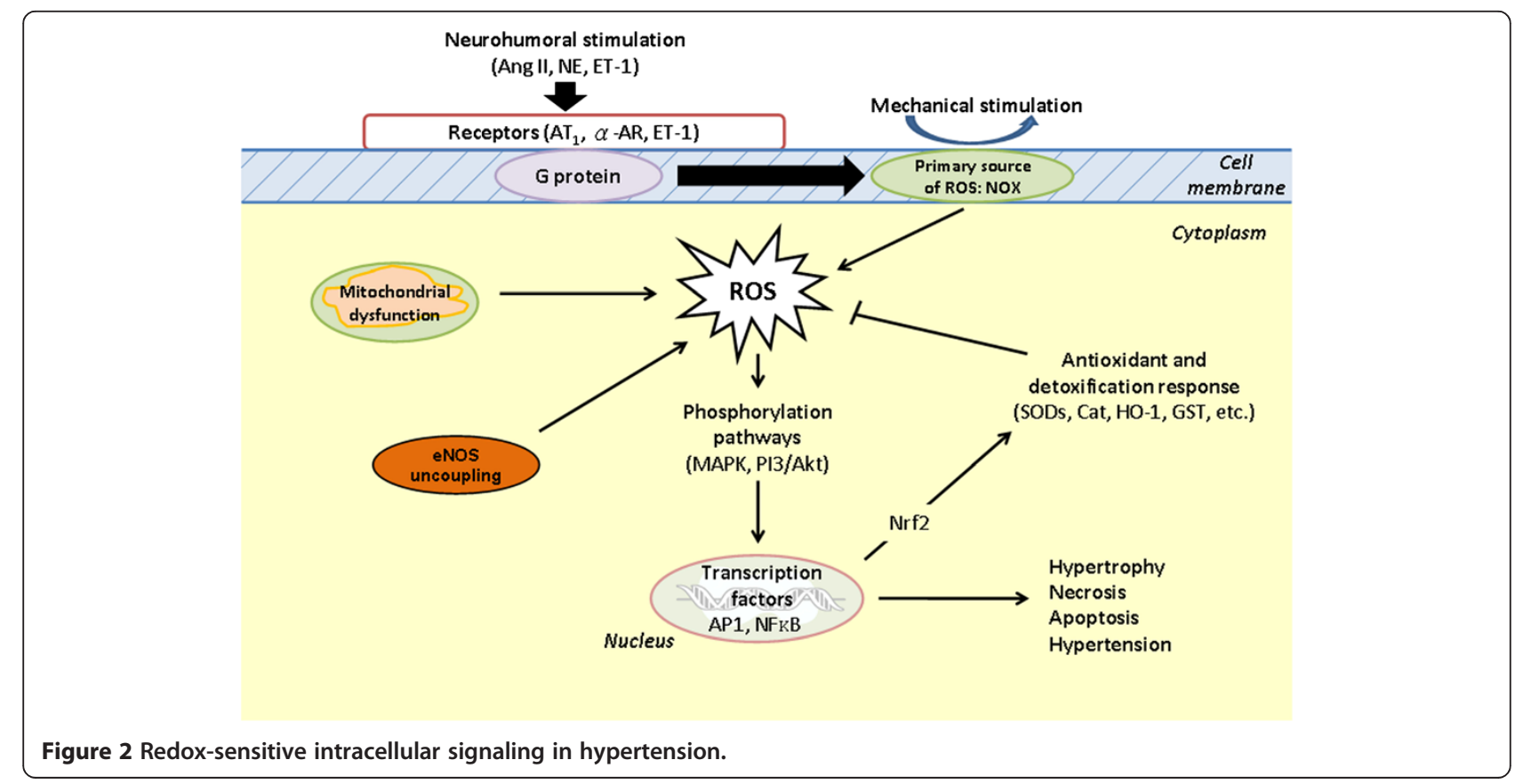


Table 1 Redox-sensitive intracellular signaling in different cells

\begin{tabular}{|c|c|c|c|c|c|}
\hline Type of cell & $\begin{array}{l}\text { Stimuli inducing production } \\
\text { of ROS }\end{array}$ & $\begin{array}{l}\text { Phosphorylation } \\
\text { pathways }\end{array}$ & $\begin{array}{l}\text { Transcription } \\
\text { factors }\end{array}$ & Effects of ROS in target cells & Ref.: \\
\hline \multirow[t]{2}{*}{ Endothelial cells } & \multirow[t]{2}{*}{ Ang $\|$} & ERKs, JNKS & NFKB & Apoptosis & \multirow[t]{2}{*}[45,46]{} \\
\hline & & p38-MAPKs & & Dysfunction & \\
\hline \multirow[t]{5}{*}{$\begin{array}{l}\text { Vascular smooth } \\
\text { muscle cells }\end{array}$} & $\begin{array}{l}\text { PDGF, phenylephrine, } \\
\text { thrombin }\end{array}$ & MAPKs & $\mathrm{NF} k \mathrm{~B}$ & Proliferation & \multirow[t]{5}{*}[45-47]{} \\
\hline & Ang ॥ & p38-MAPK & NFKB? & \multirow[t]{4}{*}{ Hypertrophy, migration } & \\
\hline & Ang II & PI3K/Akt & & & \\
\hline & ET-1 & & & & \\
\hline & Shear stress & & & & \\
\hline \multirow[t]{4}{*}{ Cardiomyocytes } & Ang \| & MAPKs & NFKB & \multirow{4}{*}{$\begin{array}{l}\text { Hypertrophy, inflammation, necrosis, } \\
\text { apoptosis }\end{array}$} & \multirow[t]{4}{*}[20]{} \\
\hline & ET-1 & PI3KAkt & AP-1 & & \\
\hline & $\mathrm{NE}$ & & p53 & & \\
\hline & Mechanical stress & & & & \\
\hline \multirow{4}{*}{$\begin{array}{l}\text { Central cardiovascular } \\
\text { neurons }\end{array}$} & Ang II & p38-MAPK, & $? ?$ & \multirow{4}{*}{$\begin{array}{l}\text { Increased sympathetic nerve activity, } \\
\text { vasopressin release, drinking behavior }\end{array}$} & \multirow[t]{4}{*}{$43,44,48$} \\
\hline & & $\underline{\text { ERK } 1 / 2}$ & & & \\
\hline & & PLC/IP3 ? & & & \\
\hline & & (or NO ?) & & & \\
\hline \multirow[t]{3}{*}{ Cells of kidney } & Ang $\|$ & MAPKs & & \multirow{3}{*}{$\begin{array}{l}\text { Augmentation of epithelial-mesenchymal } \\
\text { transition, mesangial cells apoptosis, } \\
\text { hypertrophy }\end{array}$} & \multirow[t]{3}{*}[42]{} \\
\hline & Aldosterone & $\mathrm{ERK} 1 / 2$ & & & \\
\hline & Chemokines & & & & \\
\hline
\end{tabular}

\section{Tyrosine kinases}

Activation of tyrosine kinases by ROS plays an important role in the remodeling of the cardiovascular system associated with hypertension. In vascular smooth muscle cells and other cells, the ROS activate non-receptor tyrosine kinases such as Janus kinase 2 (JAK2), proline-rich tyrosine kinase 2/cell adhesion kinase (PYK2/CAK) and Src tyrosine kinase, or the receptor tyrosine kinases, such as the receptor for epidermal growth factor (EGF) [55-57]. Particular attention is paid to the EGF receptor and JAK2 tyrosine kinase in smooth muscle cells. The EGF receptor is activated by Ang II via ROS. Its activation is necessary for activation of the ERKs and for the growth of vascular smooth muscle cells [58]. The JAK2 tyrosine kinase is also activated by Ang II and ROS and is essential for the induction of cytokines and thrombin-induced heat-shock protein in vascular smooth muscle cells and for subsequent induction of inflammatory response [59].

\section{Akt kinases}

The Akt kinase (or protein kinase B) is a serine/threonine kinase that plays an important role in many cellular processes and its activation in the PI3K/Akt pathway depends on the upstream PI3K. The activated Akt kinase phosphorylates various downstream effector molecules, such as glycogen synthase kinase-3, procaspase-9, transcription factors AP-1 and E2F [60], and is thus involved in modulation of cellular functions. The Akt kinase cascade is implicated in the processes of cell survival and its anti-apoptotic effects are mediated by phosphorylation of several proteins involved in apoptosis, such as the pro-apoptotic Bad protein. In addition to its effect on cell survival, Akt kinase plays an important role in protein synthesis, in the development of hypertrophy [61], and its activation was found to play a role in infarct size limiting mechanisms following cardiac ischemic injury [62]. Dysregulation of Akt leads to diseases of major unmet medical need such as cancer, diabetes, cardiovascular and neurological diseases [63].

The PI3K/Akt kinase signaling pathway is also involved in the metabolic control and regulation of glucose transport and glycogen synthesis. The Akt kinase can be activated by a variety of growth stimuli: the plateletderived growth factor, EGF, insulin, thrombin, and the nerve growth factor (NGF) [64]. It is also known that the oxidative stress induced by ROS is accompanied by activation of Akt kinase. Akt kinase activation by ROS and Ang II has been documented in smooth muscle cells [61]. In myocardium, Akt kinase has been considered as a reperfusion injury salvage kinase, counteracting oxidative stress-induced cell damage through a compensatory protective pathway [65]. In the RVLM of brain stem, ROS activates PI3K/Akt signaling via oxidation and phosphorylation of the phosphatase and tensin homolog deleted on chromosome 10, which is a negative regulator of PI3K signaling [66]. This redox-sensitive overactivation of PI3K/Akt signaling contributes to neural mechanisms of hypertension in SHR. Changes in Akt kinase activation 
were also observed in the doxorubicin-treated normotensive Wistar rats. Eight weeks after the treatment, the systolic blood pressure is increased, alongside with an increase in matrix metalloproteinase-2. These changes are accompanied by activation of Akt kinase, an increase in ROS accumulation, inhibition of SOD activity, induction of inducible NOS protein expression and caspase-3 activation [67]. In human endothelial cells, Akt kinase was found to phosphorylate the eNOS at serine-1177, and this is connected with eNOS activation and production of NO. The activation of eNOS through the Akt kinase was observed also by shear stress and insulin [60].

\section{RhoA/ROCK pathway}

The Rho-associated protein kinase (ROCK) is a serine/ threonine kinase. For its activity, ROCK requires the binding of the small G-protein RhoA. The RhoA/ROCK signaling pathway is stimulated by many agonists such as Ang II, thrombin, ET-1, and NE. Increased activity of this pathway was observed in atherosclerosis and pulmonary hypertension, and this signaling has been implicated in many major cardiovascular diseases such as hypertension, heart failure, and myocardial infarction. A role of this pathway in the regulation of several cellular functions such as gene expression, contraction, migration, and proliferation has been reported [68]. Moreover, it has been demonstrated that this pathway downregulates eNOS phosphorylation through inhibition of Akt kinase [69], and is involved in the modulation of eNOS gene expression by affecting the stability of its mRNA [70]. In vascular smooth muscle cells, the effects of RhoA/ROCK pathway on the decreased NO production were associated with increased vascular contractility. Moreover, inhibitors of RhoA or ROCK can decrease the systolic blood pressure in hypertensive rats [71]. Essential hypertension in human is associated with increased Rho/Rho-kinasedependent mechanisms and ROCK activity [72].

\section{Redox-sensitive transcription factors and nuclear factors in hypertension}

There are several transcription factors, including AP-1, p53, NF-kB, Nrf2, whose activity is sensitive to oxidative stress. AP-1 was first identified as a transcription factor that binds to the cis-element of the methallothionein human genes encoding proteins that are involved in cell proliferation and apoptosis in response to various stimuli, including the oxidative stress. Redox-sensitive upregulation of AP-1, c-jun or c-fos have been observed in the RVLM of the hypertensive animals [73]. In deoxycorticosterone acetate-induced hypertension, elevated inflammation and tissue damage in cardiac and vascular muscle cells are attributed to oxidative stress-associated activation of AP-1 [74]. In this animal model of hypertension, dysfunction of circulating endothelial progenitor cells is related to $\mathrm{ET}_{\mathrm{A}}$ receptor-mediated and oxidative stress-associated overexpression of $\mathrm{p} 53$ [75]. In addition, NF- $\mathrm{kB}$ activation by ROS induces the cytosolic and mitochondrial oxidative stress and tissue injury that contribute to renal dysfunction observed in SHR [76].

AP-1 binds to the antioxidant response element (ARE) of target genes, where Fos and Jun proteins may heterodimerize Nrf2 in the presence of electrophiles and oxidants [1]. Activation of gene transcription via the ARE is mediated primarily through the Nrf2 transcription factor. Under normal conditions, the activity of Nrf2 is negatively regulated by protein Kelch-like ECH associated protein 1 (Keap1) that binds to $\mathrm{Nrf} 2$ and keeps it in the cytoplasm. Exposure to xenobiotics, NO and/or ROS induce the transcription of Keap1/Nrf2/ARE-dependent genes whose functional products protect against a wide array of subsequent challenges [77]. Free Nrf2 is translocated into the nucleus, where it binds ARE enhancer and activates ARE-dependent transcription of antioxidant stress genes to trigger the cellular defense response [78,79]. Therefore, redox-sensitive activation of nuclear enhancer Nrf2 serves as a self-defense feedback mechanism to prevent sustained oxidative damage.

In addition to enzymatic degradation, detoxification of ROS and electrophiles is also important in protecting cells from oxidative damage. Genes regulated through the ARE are involved in the production of antioxidants that directly inactivate ROS (such as catalase, superoxide dismutase), detoxify xenobiotics (glutathione-S-transferase, thioredoxin, NAD $(\mathrm{P}) \mathrm{H}$ quinone oxidoreductase) and affect the production of glutathione and phase-II detoxification enzymes (e.g., $\gamma$-glutamate cystein ligase, heme oxygenase$1)$. All these genes are highly sensitive to increases in oxidative stress [80]. Moreover, several redox-sensitive kinases, such as protein kinase $\mathrm{C}, \mathrm{PI} 3 \mathrm{~K} / \mathrm{Akt}$, MAPKs, casein kinase-2 [81], are involved in the regulation of Nrf2 activity. These kinases regulate the stability and localization of Nrf2 by its phosphorylation on serine or threonine residues in a cell type-specific manner [80].

Emerging evidence indicates that activation of $\mathrm{Nrf} 2 /$ ARE signaling differs during acute versus chronic stress conditions. During acute oxidative stress, oxidized molecules modify multiple cysteine residues in Keap1, causing Nrf2 to be released from connection with Keap1. $\mathrm{Nrf} 2$ is translocated into the nucleus and induces transcription via the ARE genes [78,82]. During a prolonged oxidative stress, the activity of Nrf2 is turned off by glycogen synthase kinase $3 \beta$ (GSK3 $\beta$ ). The activated GSK3 $\beta$ phosphorylates the Fyn tyrosine kinase, causing its relocation to the nucleus [83]. Fyn phosphorylates Nrf2, which leads to expulsion of Nrf2 from the nucleus, Nrf2 binds to Keap 1 and is degraded in consequence [84]. This mechanism leads to attenuation of antioxidant and detoxificant response in long term oxidative stress. Only recently the 
involvement of this redox-sensitive regulation of Nrf2-ARE cascade gained interest on its role in pathogenesis of oxidative stress-associated hypertension. The mammalian Nox4 of the NADPH oxidase possesses antioxidant activity through $\mathrm{Nrf} 2$-dependent upregulation of antioxidant heme oxygenase-1 (HO-1) [85]. Catalase overexpression ameliorates maternal diabetes-induced perinatal programming and development of hypertension in adulthood, mediated, at least in part, by triggering the Nrf2-HO-1 defense system [86]. On the other hand, Nrf2-deficient mice show reduced pulmonary expression of antioxidant glutathione, and this renders them highly susceptible to hyperoxia-induced oxidative lung injury [87].

\section{SOD isoforms and management of hypertension}

For the cell to maintain ROS homeostasis there is a delicate balance existing between the production and degradation of the radicals $[88,89]$. The later involves activation of SOD isoforms, which are the first natural antioxidant defense proteins that improve redox balance. There are three SOD isoforms, namely the cytosolic copper-zinc SOD (CuZnSOD, or SOD1), mitochondrial manganese SOD (MnSOD, or SOD2), and the extracellular SOD (ecSOD, SOD3). They are the products of different genes, but catalyze the same reaction for dismutation of $\mathrm{O}_{2}^{-*}$ to $\mathrm{H}_{2} \mathrm{O}_{2}$ [90]. The SOD function as a signaling molecule in blood vessels and cardiomyocytes have been discussed $[15,91]$. Applications of antioxidant gene therapies based on the SOD genes, $\mathrm{HO}-1$ gene, or glutathione peroxidase gene in cardiovascular diseases have been presented and summarized [92]. Application of individual SOD isoform in the therapy of hypertension has been described [93].

Zimmerman et al. [94] were the first to report in vivo gene delivery of adenoviral vectors encoding SOD1. They found that both superoxide production from Ang II infusion and the induced hypertension were prevented by overexpression of CuZnSOD. A causal relationship between biochemical correlates of oxidative stress and neurological hypertension was established after a gene transfer by microinjection of adenovirus encoding SOD1, SOD2 or catalase into the RVLM, which promotes a longterm reduction of blood pressure in SHR [95]. In consistent to the findings, a gene therapy based on SOD1 gene transduction by a bacterial gene delivery system results in blood pressure decrease, regulation of SOD and NOS activities, and a protection against oxidative stress [96].

SOD2 is present mainly in the mitochondria of endothelial cells and less in mitochondria of vascular smooth muscle cells [90]. Mitochondrial oxidative damage is one of the main pathogenic cellular mechanisms involved in pathogenesis of hypertension, making the selective targeting of the mitochondria with potent antioxidants a promising approach in the therapeutic strategy of these diseases. Overexpression of SOD2 reduces oxidative stress in mitochondria and promotes antihypertensive effects [90]. Preservation of the mitochondrial electron transport capacity in RVLM with a highly mobile electron carrier, CoQ10, reduces arterial pressure in SHR and attenuates the pressor response of normotensive Wistar-Kyoto rats to Ang II infusion [7,33]. Transgenic mice with SOD2 overexpression attenuates hypertension induced by Ang II [97]. This situation is similar to mice treated with mitochondrial-targeted antioxidant mitoTEMPO, while non-target antioxidant TEMPOL was not effective [98]. Reduction in oxidative stress by intravenous transduction of cDNA of the SOD1 and SOD2 genes leads to a decrease in blood pressure, reversal of neuronal NOS gene upregulation in the left ventricle, and a decreased mitochondrial damage in adult SHR [99].

SOD3 is located in the extracellular space and binds to the cell membrane through a heparin-binding domain. It is the second most abundant SOD isoform in blood vessels and is produced mainly by smooth muscle cells. SOD3 is very important in endothelium-mediated vasodilation because of its location in the interstitium between endothelial cells and vascular smooth muscle cells. It enables safe diffusion of $\mathrm{NO}$ from endothelial cells into smooth muscle cells [100]. EcSOD-deficient mice have significantly higher degree of hypertrophy, ventricular dilation and myocardial fibrosis [101]. Studies using overexpression revealed the protective effects of SOD3 in the blood vessels. Gene transfer of SOD3-encoding cDNA reduces superoxide levels in blood vessels and decreases arterial pressure in SHR [102].

\section{Conclusions}

Radical signaling offers several possibilities and strategies of modulating ROS homeostasis in the management of hypertension. Individual SOD isoforms can be influenced using gene transduction and SOD mimetics. Other strategies include inhibition of NADPH oxidase activity, preservation of mitochondrial electron transport chain capacity, increases in $\mathrm{BH}_{4}$, modulation of the signaling and phosphorylation pathways, such as MAPK, Akt kinase, and RhoA/ROCK signaling pathways. All these possibilities and strategies have been reported to alleviate ROS accumulation and to protect against oxidative stress to a different degree in the animal models of hypertension. In addition, modulation of the redox-sensitive transcription factors, as well as stimulation of antioxidant response through the Nrf2-ARE pathway may also prove to be a useful strategy in future. All these possibilities and strategies should be further studied in the search for new therapeutical approaches in management of hypertension.

\section{Abbreviations}

Akt kinase: Serine/threonine protein kinase; Ang II: Angiotensin II;

AP-1: Activator protein 1; ARE: Antioxidant response element;

$A T_{1} R$ : Angiotensin type 1 receptor; $a_{1}-A R$ : alpha ${ }_{1}$-adrenergic receptors; 
$\mathrm{BH}_{4}$ : Tetrahydrobiopterin; CoQ: Coenzyme Q; Cu/Zn SOD: Cupper/zinc superoxide dismutase; ecSOD: extracellular superoxide dismutase; EGF: Epidermal growth factor; eNOS: endothelial nitric oxidase synthase: ERK: Extracellular signal-regulated kinase; ET-1: Endothelin-1; GSK33: Glycogen synthase kinase-3 $\beta_{;} \mathrm{H}_{2} \mathrm{O}_{2}$ : Hydrogen peroxide; $\mathrm{HO}-1$ : Heme oxygenase-1; JAK2: Janus kinase 2; JNK: c-Jun N-terminal kinase; Keap1: Kelch-like ECH associated protein 1; NADPH oxidase: Nicotinamide adenine dinucleotide phosphate oxidase; MAPK: Mitogen activated protein kinase; MnSOD: Manganese superoxide dismutase; NE: Norepinephrine; NF-KB: Nuclear factor kappa B; NGF: Nerve growth factor; NO: Nitric oxide; NOS: Nitric oxide synthase; Nrf2: Nuclear transcription factor E2-related factor 2; O2-: Superoxide; PI3K/Akt: Phosphoinositol-3-kinase/Akt kinase; PYK2/ CAK: Proline - rich tyrosine kinase 2/cell adhesion kinase; RAS: Renin-angiotensin system; RhoA: Small G-protein RhoA; RNS: Reactive nitrogen species; ROCK: Rho-associated protein kinase (serine/threonine kinase); ROS: Reactive oxygen species; RVLM: Rostral ventrolateral medulla; SHR: Spontaneously hypertensive rats.

\section{Competing interests}

The authors declare that they have no competing interests.

\section{Authors' contributions}

$M M, I D, M B$, and JYHC collected information and prepared manuscript. MM and JYHC prepared the figures, ID, MB and JYHC finalized the manuscript. All authors read and approved the final manuscript.

\section{Acknowledgment}

This work is supported by grant SAS-NSC JRP 2010/1 (ID), Slovakia and NSC100-2923-B075B-001-MY3 (JYHC) from the National Science Council, Taiwan.

\section{Author details}

'Institute of Normal and Pathological Physiology, Slovak Academy of Sciences, Sienkiewiczova 1, 81371 Bratislava, Slovakia. ${ }^{2}$ Institute for Heart Research, Slovak Academy of Sciences, Bratislava, Slovakia. ${ }^{3}$ Center for Translational Research in Biomedical Sciences, Kaohsiung Chang Gang Memorial Hospital, Kaohsiung, Taiwan.

Received: 17 June 2013 Accepted: 14 September 2013

Published: 18 September 2013

\section{References}

1. Wright CJ, Dennery PA: Manipulation of gene expression by oxygen: a primer from bedside to bench. Pediatr Res 2009, 66:3-10.

2. Paravicini TM, Touyz RM: NADPH oxidases, reactive oxygen species, and hypertension: clinical implications and therapeutic possibilities. Diabetes Care 2008, 31(Suppl 2):S170-S180.

3. Forman HJ, Fukuto JM, Miller T, Zhang H, Rinna A, Levy S: The chemistry of cell signaling by reactive oxygen and nitrogen species and 4-hydroxynonenal. Arch Biochem Biophys 2008, 477:183-195.

4. Greene EL, Lu G, Zhang D, Egan BM: Signaling events mediating the additive effects of oleic acid and angiotensin II on vascular smooth muscle cell migration. Hypertension 2001, 37:308-312.

5. Maki J, Hirano M, Hoka S, Kanaide H, Hirano K: Involvement of reactive oxygen species in thrombin-induced pulmonary vasoconstriction. Am J Respir Crit Care Med 2010, 182:1435-1444.

6. Tsai $\mathrm{MH}$, Jiang MJ: Reactive oxygen species are involved in regulating alpha1-adrenoceptor-activated vascular smooth muscle contraction. J Biomed Sci 2010, 17:67.

7. Chan SH, Chan JY: Angiotensin-generated reactive oxygen species in brain and pathogenesis of cardiovascular diseases. Antioxid Redox Signal 2013, 19:1074-1084

8. Harrison DG, Gongora MC: Oxidative stress and hypertension. Med Clin North Am 2009, 93:621-635.

9. Hirooka Y, Kishi T, Sakai K, Takeshita A, Sunagawa K: Imbalance of central nitric oxide and reactive oxygen species in the regulation of sympathetic activity and neural mechanisms of hypertension. Am J Physiol Regul Integr Comp Physiol 2011, 300:R818-R826.

10. Schulz E, Gori T, Munzel T: Oxidative stress and endothelial dysfunction in hypertension. Hypertens Res 2011, 34:665-673.
11. Amanso AM, Griendling KK: Differential roles of NADPH oxidases in vascular physiology and pathophysiology. Front Biosci (Schol Ed) 2012, 4:1044-1064.

12. Montezano AC, Touyz RM: Reactive oxygen species and endothelial function-role of nitric oxide synthase uncoupling and Nox family nicotinamide adenine dinucleotide phosphate oxidases. Basic Clin Pharmacol Toxicol 2012, 110:87-94.

13. Rodrigo R, Gonzalez J, Paoletto F: The role of oxidative stress in the pathophysiology of hypertension. Hypertens Res 2011, 34:431-440.

14. Touyz RM, Briones AM: Reactive oxygen species and vascular biology: implications in human hypertension. Hypertens Res 2011, 34:5-14.

15. Gongora MC, Harrison DG: Sad heart from no SOD. Hypertension 2008, 51:28-30.

16. Harrison DG, Chen W, Dikalov S, Li L: Regulation of endothelial cell tetrahydrobiopterin pathophysiological and therapeutic implications. Adv Pharmacol 2010, 60:107-132.

17. Griendling KK, Sorescu D, Lassegue B, Ushio-Fukai M: Modulation of protein kinase activity and gene expression by reactive oxygen species and their role in vascular physiology and pathophysiology. Arterioscler Thromb Vasc Biol 2000, 20:2175-2183.

18. Loomis ED, Sullivan JC, Osmond DA, Pollock DM, Pollock JS: Endothelin mediates superoxide production and vasoconstriction through activation of NADPH oxidase and uncoupled nitric-oxide synthase in the rat aorta. J Pharmacol Exp Ther 2005, 315:1058-1064.

19. Gomez-Alamillo C, Juncos LA, Cases A, Haas JA, Romero JC: Interactions between vasoconstrictors and vasodilators in regulating hemodynamics of distinct vascular beds. Hypertension 2003, 42:831-836.

20. Balakumar P, Jagadeesh G: Multifarious molecular signaling cascades of cardiac hypertrophy: can the muddy waters be cleared? Pharmacol Res 2010, 62:365-383.

21. Dammanahalli KJ, Sun Z: Endothelins and NADPH oxidases in the cardiovascular system. Clin Exp Pharmacol Physiol 2008, 35:2-6.

22. Hirooka Y: Role of reactive oxygen species in brainstem in neural mechanisms of hypertension. Auton Neurosci 2008, 142:20-24.

23. Nguyen Dinh Cat A, Touyz RM: Cell signaling of angiotensin II on vascular tone: novel mechanisms. Curr Hypertens Rep 2011, 13:122-128.

24. Zweier JL, Chen CA, Druhan LJ: S-glutathionylation reshapes our understanding of endothelial nitric oxide synthase uncoupling and nitric oxide/reactive oxygen species-mediated signaling. Antioxid Redox Signal 2011, 14:1769-1775.

25. Moens AL, Kass DA: Tetrahydrobiopterin and cardiovascular disease. Arterioscler Thromb Vasc Biol 2006, 26:2439-2444

26. Rochette L, Lorin J, Zeller M, Guilland JC, Lorgis L, Cottin Y, Vergely C: Nitric oxide synthase inhibition and oxidative stress in cardiovascular diseases: Possible therapeutic targets? Pharmacol Ther 2013: in press.

27. Roe ND, Ren J: Nitric oxide synthase uncoupling: a therapeutic target in cardiovascular diseases. Vascul Pharmacol 2012, 57:168-172.

28. Zuckerbraun BS, George P, Gladwin MT: Nitrite in pulmonary arterial hypertension: therapeutic avenues in the setting of dysregulated arginine/nitric oxide synthase signalling. Cardiovasc Res 2011, 89:542-552

29. Radi R, Cassina A, Hodara R, Quijano C, Castro L: Peroxynitrite reactions and formation in mitochondria. Free Radic Biol Med 2002, 33:1451-1464

30. MacMillan-Crow LA, Crow JP, Thompson JA: Peroxynitrite-mediated inactivation of manganese superoxide dismutase involves nitration and oxidation of critical tyrosine residues. Biochemistry 1998, 37:1613-1622.

31. Andrukhiv A, Costa AD, West IC, Garlid KD: Opening mitoKATP increases superoxide generation from complex I of the electron transport chain. Am J Physiol Heart Circ Physiol 2006, 291:H2067-H2074.

32. Brandes RP: Triggering mitochondrial radical release: a new function for NADPH oxidases. Hypertension 2005, 45:847-848.

33. Chan SH, Wu KL, Chang AY, Tai MH, Chan JY: Oxidative impairment of mitochondrial electron transport chain complexes in rostral ventrolateral medulla contributes to neurogenic hypertension. Hypertension 2009, 53:217-227.

34. Abhijit S, Bhaskaran R, Narayanasamy A, Chakroborty A, Manickam N, Dixit M, Mohan V, Balasubramanyam M: Hyperinsulinemia-induced vascular smooth muscle cell (VSMC) migration and proliferation is mediated by converging mechanisms of mitochondrial dysfunction and oxidative stress. Mol Cell Biochem 2013, 373:95-105. 
35. Sumbalova Z, Kucharska J, Kristek F: Losartan improved respiratory function and coenzyme $Q$ content in brain mitochondria of young spontaneously hypertensive rats. Cell Mol Neurobiol 2010, 30:751-758.

36. Waypa GB, Marks JD, Guzy R, Mungai PT, Schriewer J, Dokic D, Schumacker PT: Hypoxia triggers subcellular compartmental redox signaling in vascular smooth muscle cells. Circ Res 2010, 106:526-535.

37. Waypa GB, Marks JD, Guzy RD, Mungai PT, Schriewer JM, Dokic D, Ball MK, Schumacker PT: Superoxide generated at mitochondrial complex III triggers acute responses to hypoxia in the pulmonary circulation. Am J Respir Crit Care Med 2013, 187:424-432.

38. Wosniak J Jr, Santos CX, Kowaltowski AJ, Laurindo FR: Cross-talk between mitochondria and NADPH oxidase: effects of mild mitochondrial dysfunction on angiotensin II-mediated increase in Nox isoform expression and activity in vascular smooth muscle cells. Antioxid Redox Signal 2009, 11:1265-1278

39. Chan SH, Wu CW, Chang AY, Hsu KS, Chan JY: Transcriptional upregulation of brain-derived neurotrophic factor in rostral ventrolateral medulla by angiotensin II: significance in superoxide homeostasis and neural regulation of arterial pressure. Circ Res 2010, 107:1127-1139.

40. Foster DB, Van Eyk JE, Marban E, O'Rourke B: Redox signaling and protein phosphorylation in mitochondria: progress and prospects. J Bioenerg Biomembr 2009, 41:159-168.

41. Finkel T: Signal transduction by reactive oxygen species. J Cell Bio/ 2011, 194:7-15.

42. Nistala R, Whaley-Connell A, Sowers JR: Redox control of renal function and hypertension. Antioxid Redox Signal 2008, 10:2047-2089.

43. Infanger DW, Sharma RV, Davisson RL: NADPH oxidases of the brain: distribution, regulation, and function. Antioxid Redox Signal 2006, 8:1583-1596.

44. Zimmerman MC, Davisson RL: Redox signaling in central neural regulation of cardiovascular function. Prog Biophys Mol Biol 2004, 84:125-149.

45. Irani K: Oxidant signaling in vascular cell growth, death, and survival : a review of the roles of reactive oxygen species in smooth muscle and endothelial cell mitogenic and apoptotic signaling. Circ Res 2000, 87:179-183.

46. Lee MY, Griendling KK: Redox signaling, vascular function, and hypertension. Antioxid Redox Signal 2008, 10:1045-1059.

47. Gusan S, Anand-Srivastava MB: CAMP attenuates the enhanced expression of Gi proteins and hyperproliferation of vascular smooth muscle cells from SHR: role of ROS and ROS-mediated signaling. Am J Physio/ Cell Physiol 2013, 304:C1198-C1209.

48. Campos RR: Oxidative stress in the brain and arterial hypertension. Hypertens Res 2009, 32:1047-1048.

49. Boutros T, Chevet E, Metrakos P: Mitogen-activated protein (MAP) kinase/ MAP kinase phosphatase regulation: roles in cell growth, death, and cancer. Pharmacol Rev 2008, 60:261-310.

50. Haagenson KK, Wu GS: The role of MAP kinases and MAP kinase phosphatase- 1 in resistance to breast cancer treatment. Cancer Metastasis Rev 2010, 29:143-149.

51. Paravicini TM, Touyz RM: Redox signaling in hypertension. Cardiovasc Res 2006, 71:247-258

52. Son Y, Cheong YK, Kim NH, Chung HT, Kang DG, Pae HO: Mitogenactivated protein kinases and reactive oxygen species: how can ROS activate MAPK pathways? J Signal Transduct 2011, 2011:792639.

53. Torres M, Forman HJ: Redox signaling and the MAP kinase pathways. Biofactors 2003, 17:287-296.

54. Muslin AJ: MAPK signalling in cardiovascular health and disease: molecular mechanisms and therapeutic targets. Clin Sci (Lond) 2008, 115:203-218.

55. Abe J, Berk BC: Fyn and JAK2 mediate Ras activation by reactive oxygen species. J Biol Chem 1999, 274:21003-21010.

56. Frank GD, Eguchi S, Yamakawa T, Tanaka S, Inagami T, Motley ED: Involvement of reactive oxygen species in the activation of tyrosine kinase and extracellular signal-regulated kinase by angiotensin II. Endocrinology 2000, 141:3120-3126.

57. Wang $\mathrm{S}$, Zhu $\mathrm{H}$, Chen $\mathrm{C}$ : Reactive oxygen species contribute to the induction of superoxide dismutase during heat shock in cultured rat neonatal cardiomyocytes. Chin Med J (Engl) 2000, 113:606-609.

58. Eguchi S, Iwasaki H, Ueno H, Frank GD, Motley ED, Eguchi K, Marumo F, Hirata Y, Inagami T: Intracellular signaling of angiotensin II-induced p70 S6 kinase phosphorylation at Ser(411) in vascular smooth muscle cells.
Possible requirement of epidermal growth factor receptor, Ras, extracellular signal-regulated kinase, and Akt. J Biol Chem 1999, 274:36843-36851.

59. Madamanchi NR, Li S, Patterson C, Runge MS: Thrombin regulates vascular smooth muscle cell growth and heat shock proteins via the JAK-STAT pathway. J Biol Chem 2001, 276:18915-18924.

60. Coffer PJ, Jin J, Woodgett JR: Protein kinase B (c-Akt): a multifunctional mediator of phosphatidylinositol 3-kinase activation. Biochem J 1998 335(Pt 1):1-13

61. Ushio-Fukai M, Alexander RW, Akers M, Yin Q, Fujio Y, Walsh K, Griendling KK: Reactive oxygen species mediate the activation of Akt/protein kinase B by angiotensin II in vascular smooth muscle cells. J Biol Chem 1999, 274:22699-22704.

62. Ravingerova T, Matejikova J, Neckar J, Andelova E, Kolar F: Differential role of PI3K/Akt pathway in the infarct size limitation and antiarrhythmic protection in the rat heart. Mol Cell Biochem 2007, 297:111-120.

63. Hers I, Vincent EE, Tavare JM: Akt signalling in health and disease. Cell Signal 2011, 23:1515-1527.

64. Downward J: Mechanisms and consequences of activation of protein kinase B/Akt. Curr Opin Cell Biol 1998, 10:262-267.

65. Halestrap AP, Clarke SJ, Khaliulin I: The role of mitochondria in protection of the heart by preconditioning. Biochim Biophys Acta 2007 1767:1007-1031

66. Wu KL, Wu CA, Wu CW, Chan SH, Chang AY, Chan JY: Redox-sensitive oxidation and phosphorylation of PTEN contribute to enhanced activation of PI3K/Akt signaling in rostral ventrolateral medulla and neurogenic hypertension in spontaneously hypertensive rats. Antioxid Redox Signal 2013, 18:36-50.

67. Ivanova M, Dovinova I, Okruhlicova L, Tribulova N, Simoncikova P, Barte-kova M, Vlkovicova J, Barancik M: Chronic cardiotoxicity of doxorubicin involves activation of myocardial and circulating matrix metalloproteinases in rats. Acta Pharmacol Sin 2012, 33:459-469.

68. Amin E, Dubey BN, Zhang SC, Gremer L, Dvorsky R, Moll JM, Taha MS, Nagel-Steger L, Piekorz RP, Somlyo AV, Ahmadian MR: Rho-kinase: regulation, (dys)function, and inhibition. Biol Chem 2013: . in press.

69. Wolfrum S, Dendorfer A, Rikitake Y, Stalker TJ, Gong Y, Scalia R, Dominiak P, Liao JK: Inhibition of Rho-kinase leads to rapid activation of phosphatidylinositol 3-kinase/protein kinase Akt and cardiovascular protection. Arterioscler Thromb Vasc Biol 2004, 24:1842-1847.

70. Eto M, Barandier C, Rathgeb L, Kozai T, Joch H, Yang Z, Luscher TF: Thrombin suppresses endothelial nitric oxide synthase and upregulates endothelin-converting enzyme-1 expression by distinct pathways: role of Rho/ROCK and mitogen-activated protein kinase. Circ Res 2001, 89:583-590.

71. Wirth A: Rho kinase and hypertension. Biochim Biophys Acta 1802, 2010:1276-1284

72. Smith CJ, Santhanam L, Alexander LM: Rho-Kinase activity and cutaneous vasoconstriction is upregulated in essential hypertensive humans. Microvasc Res 2013, 87:58-64.

73. Chan SH, Wang LL, Tseng HL, Chan JY: Upregulation of AT1 receptor gene on activation of protein kinase Cbeta/nicotinamide adenine dinucleotide diphosphate oxidase/ERK1/2/c-fos signaling cascade mediates long-term pressor effect of angiotensin II in rostral ventrolateral medulla. J Hypertens 2007, 25:1845-1861.

74. Jadhav A, Torlakovic E, Ndisang JF: Interaction among heme oxygenase, nuclear factor-kappaB, and transcription activating factors in cardiac hypertrophy in hypertension. Hypertension 2008, 52:910-917.

75. Chen DD, Dong YG, Yuan H, Chen AF: Endothelin 1 activation of endothelin A receptor/NADPH oxidase pathway and diminished antioxidants critically contribute to endothelial progenitor cell reduction and dysfunction in salt-sensitive hypertension. Hypertension 2012, 59:1037-1043.

76. Elks CM, Mariappan N, Haque M, Guggilam A, Majid DS, Francis J: Chronic NF-\{kappa\}B blockade reduces cytosolic and mitochondrial oxidative stress and attenuates renal injury and hypertension in SHR. Am J Physiol Renal Physiol 2009, 296:F298-F305.

77. Calabrese V, Signorile A, Cornelius C, Mancuso C, Scapagnini G, Ventimiglia B, Ragusa N, Dinkova-Kostova A: Practical approaches to investigate redox regulation of heat shock protein expression and intracellular glutathione redox state. Methods Enzymol 2008, 441:83-110.

78. Hur W, Sun Z, Jiang T, Mason DE, Peters EC, Zhang DD, Luesch H, Schultz PG Gray NS: A small-molecule inducer of the antioxidant response element. Chem Biol 2010, 17:537-547. 
79. Venugopal R, Jaiswal AK: Nrf2 and Nrf1 in association with Jun proteins regulate antioxidant response element-mediated expression and coordinated induction of genes encoding detoxifying enzymes. Oncogene 1998, 17:3145-3156.

80. Hur W, Gray NS: Small molecule modulators of antioxidant response pathway. Curr Opin Chem Biol 2011, 15:162-173.

81. Apopa PL, He X, Ma Q: Phosphorylation of Nrf2 in the transcription activation domain by casein kinase 2 (CK2) is critical for the nuclear translocation and transcription activation function of Nrf2 in IMR-32 neuroblastoma cells. J Biochem Mol Toxicol 2008, 22:63-76.

82. Tkachev VO, Menshchikova EB, Zenkov NK: Mechanism of the Nrf2/Keap1/ ARE signaling system. Biochemistry (Mosc) 2011, 76:407-422.

83. Jain AK, Jaiswal AK: GSK-3beta acts upstream of Fyn kinase in regulation of nuclear export and degradation of NF-E2 related factor 2. J Biol Chem 2007, 282:16502-16510.

84. Kanninen K, White AR, Koistinaho J, Malm T: Targeting glycogen synthase kinase-3beta for therapeutic benefit against oxidative stress in alzheimer's disease: involvement of the Nrf2-ARE pathway. Int J Alzheimers Dis 2011, 2011:985085.

85. Schroder K, Zhang M, Benkhoff S, Mieth A, Pliquett R, Kosowski J, Kruse C, Luedike $P$, Michaelis UR, Weissmann N, et al: Nox4 is a protective reactive oxygen species generating vascular NADPH oxidase. Circ Res 2012, 110:1217-1225

86. Chang SY, Chen YW, Zhao XP, Chenier I, Tran S, Sauve A, Ingelfinger JR, Zhang SL: Catalase prevents maternal diabetes-induced perinatal programming via the Nrf2-HO-1 defense system. Diabetes 2012, 61:2565-2574.

87. Reddy NM, Kleeberger SR, Cho HY, Yamamoto M, Kensler TW, Biswal S, Reddy SP: Deficiency in Nrf2-GSH signaling impairs type II cell growth and enhances sensitivity to oxidants. Am J Respir Cell Mol Biol 2007, 37:3-8.

88. Dovinova I, Cacanyiova S, Faberova V, Kristek F: The effect of an NO donor, pentaerythrityl tetranitrate, on biochemical, functional, and morphological attributes of cardiovascular system of spontaneously hypertensive rats. Gen Physiol Biophys 2009, 28:86-93.

89. Dovinova I, Gardlik R, Palffy R, Kristek F, Cacanyiova S, Vantova Z, Paulikova H: Modulation of antioxidative response in the therapy of hypertension and other cardiovascular diseases. Neuro Endocrinol Lett 2009, 30(Suppl 1):32-35.

90. Faraci FM, Didion SP: Vascular protection: superoxide dismutase isoforms in the vessel wall. Arterioscler Thromb Vasc Biol 2004, 24:1367-1373.

91. Mendez JI, Nicholson WJ, Taylor WR: SOD isoforms and signaling in blood vessels: evidence for the importance of ROS compartmentalization. Arterioscler Thromb Vasc Biol 2005, 25:887-888.

92. Levonen AL, Vahakangas E, Koponen JK, Yla-Herttuala S: Antioxidant gene therapy for cardiovascular disease: current status and future perspectives. Circulation 2008, 117:2142-2150.

93. Gardlik R, Dovinová I, Chan JY: Approaches in gene therapy of cancer and cardiovascular diseases. In Gene Therapy Applications. Edited by Rijeka CK. Croatia: InTech; 2011:59-84.

94. Zimmerman MC, Lazartigues E, Sharma RV, Davisson RL: Hypertension caused by angiotensin II infusion involves increased superoxide production in the central nervous system. Circ Res 2004, 95:210-216.

95. Chan SH, Tai MH, Li CY, Chan JY: Reduction in molecular synthesis or enzyme activity of superoxide dismutases and catalase contributes to oxidative stress and neurogenic hypertension in spontaneously hypertensive rats. Free Radic Biol Med 2006, 40:2028-2039.

96. Dovinová I, Pálffy R, Gardlik R, Vrankova S, Jendekova L, Kristek F, Sumbalova Z, Paulíkova $\mathrm{H}$ : Antioxidant gene treatment of hypertension in spontaneously hypertensive rats. In Abstract Book of Satellite symposium to the 22nd Scientific Meeting of International Society of Hypertension: 12-13 June 2008. Edited by Pechanova O. Bratislava: Institute of Normal and Pathological Physiology SAS; 2008:47-48.

97. Carlstrom M, Lai EY, Ma Z, Steege A, Patzak A, Eriksson UJ, Lundberg JO, Wilcox CS, Persson AE: Superoxide dismutase 1 limits renal microvascular remodeling and attenuates arteriole and blood pressure responses to angiotensin II via modulation of nitric oxide bioavailability. Hypertension 2010, 56:907-913.

98. Dikalova AE, Bikineyeva AT, Budzyn K, Nazarewicz RR, McCann L, Lewis W, Harrison DG, Dikalov SI: Therapeutic targeting of mitochondrial superoxide in hypertension. Circ Res 2010, 107:106-116.
99. Dovinova I, Barančík M, Čačányiová S, Kristek F, Gajdošechová L, Gardlík R: Changes in antioxidant response and ROS signaling in different experimental hypertension models. J Hypertens 2011, 29(Suppl B):e45.

100. Fukai T, Folz RJ, Landmesser U, Harrison DG: Extracellular superoxide dismutase and cardiovascular disease. Cardiovasc Res 2002, 55:239-249.

101. Gongora MC, Qin Z, Laude K, Kim HW, McCann L, Folz JR, Dikalov S, Fukai T, Harrison DG: Role of extracellular superoxide dismutase in hypertension. Hypertension 2006, 48:473-481.

102. Chu Y, lida S, Lund DD, Weiss RM, DiBona GF, Watanabe Y, Faraci FM, Heistad DD: Gene transfer of extracellular superoxide dismutase reduces arterial pressure in spontaneously hypertensive rats: role of heparin-binding domain. Circ Res 2003, 92:461-468.

doi:10.1186/1423-0127-20-69

Cite this article as: Majzunova et al:: Redox signaling in pathophysiology of hypertension. Journal of Biomedical Science 2013 20:69.

\section{Submit your next manuscript to BioMed Central and take full advantage of:}

- Convenient online submission

- Thorough peer review

- No space constraints or color figure charges

- Immediate publication on acceptance

- Inclusion in PubMed, CAS, Scopus and Google Scholar

- Research which is freely available for redistribution

Submit your manuscript at www.biomedcentral.com/submit
C) Biomed Central 